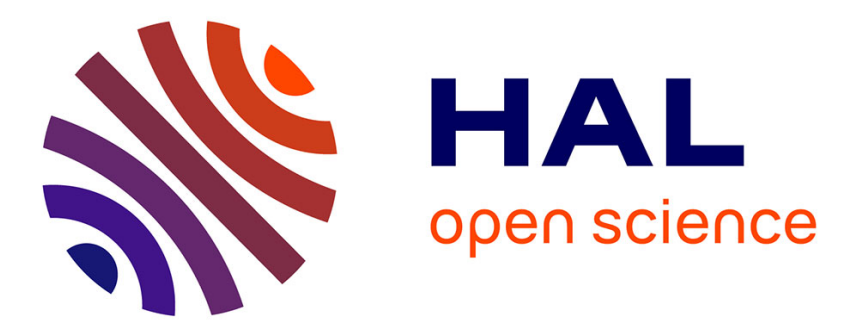

\title{
Nanoscale multipolar chromophores for optical limiting in the visible-NIR range based on multiphoton absorption
}

Olivier Mongin, Marina Charlot, Claudine Katan, Laurent Porrès, Manuel Parent, Thomas Pons, Jerome Mertz, Mireille Blanchard-Desce

\section{To cite this version:}

Olivier Mongin, Marina Charlot, Claudine Katan, Laurent Porrès, Manuel Parent, et al.. Nanoscale multipolar chromophores for optical limiting in the visible-NIR range based on multiphoton absorption. Proceedings of SPIE, the International Society for Optical Engineering, 2004, Nonlinear Optical Transmission and Multiphoton Processes in Organics II, 5516, pp.9-20. 10.1117/12.559937 . hal01417574

HAL Id: hal-01417574

https://hal-univ-rennes1.archives-ouvertes.fr/hal-01417574

Submitted on 15 Dec 2016

HAL is a multi-disciplinary open access archive for the deposit and dissemination of scientific research documents, whether they are published or not. The documents may come from teaching and research institutions in France or abroad, or from public or private research centers.
L'archive ouverte pluridisciplinaire HAL, est destinée au dépôt et à la diffusion de documents scientifiques de niveau recherche, publiés ou non, émanant des établissements d'enseignement et de recherche français ou étrangers, des laboratoires publics ou privés. 


\title{
Nanoscale multipolar chromophores for optical limiting in the visible- NIR range based on multiphoton absorption
}

\author{
Olivier Mongin ${ }^{\mathrm{a}}$, Marina Charlot, ${ }^{\mathrm{a}}$ Claudine Katan, ${ }^{\mathrm{a}}$ Laurent Porrès ${ }^{\mathrm{a}}$, Manuel Parent ${ }^{\mathrm{a}}$, Thomas Pons ${ }^{\mathrm{b}}$, \\ Jerome Mertz ${ }^{b}$ and Mireille Blanchard-Desce ${ }^{{ }^{a} a}$ \\ ${ }^{a}$ Synthèse et Electrosynthèse Organiques (UMR CNRS 6510), Institut de Chimie, Université de Rennes 1, \\ Campus Scientifique de Beaulieu, Bât. 10A, 35042 Rennes, France; \\ ${ }^{\mathrm{b}}$ Neurophysiologie et Nouvelles Microscopies (INSERM U603, CNRS FRE 2500), Ecole Supérieure de \\ Physique et Chimie Industrielles, 10 rue Vauquelin, F-75231 Paris Cedex 05, France
}

\begin{abstract}
A series of structurally-related multipolar chromophores of different symmetry (dipolar, quadrupolar, octupolar, dendritic...), and shape (rod-like, Y-shaped...) propeller-shaped, were investigated for optical power limiting based on multiphoton absorption processes. Their design is based on the functionalization of nanoscale linear or branched conjugated backbones with electro-active (i.e. electron-releasing or electron-withdrawing) peripheral and core/node groups. Their two-photon absorption (TPA) spectra were determined by investigating their two-photon-excited fluorescence properties in the NIR region using pulsed excitation in the femtosecond regime. These studies provide evidence that the charge symmetry plays an important role, the quadrupolar chromophores leading to giant TPA crosssections in the visible red. Furthermore, modulation of the nonlinear absorptivity/transparency/photostability trade-off can be achieved by playing on the nature of the electroactive groups and of the spacers. Interestingly, higher-order charge symmetries and branched structures provide an innovative route for TPA amplification and/or spectral broadening in the NIR region.
\end{abstract}

Keywords: Two-photon absorption, multipolar structures, nanoscale systems, branched-structures, optical limitation

\section{INTRODUCTION}

Multiphoton absorption has attracted considerable attention for optical power limiting applications. ${ }^{1-4}$ This nonlinear process offers the possibility of maintaining high transparency in ambient light and achieving efficient and instantaneous protection against the high intensity delivered by high power lasers. Key ingredients for such purpose are a high transmission at low intensity (i.e. weak linear absorption) and high multiphoton absorption cross-sections (i.e. high nonlinear responses). In this context, we have focused on the design of chromophores showing very large two-photon absorption (TPA) cross-sections $\left(\sigma_{2}\right)$ while maintaining wide transparency in the visible and/or NIR spectral range. Large one-photon excited-state cross-section $\left(\sigma_{e}\right)$ and long excited-state lifetime are also desirable to allow two-photon induced excited-state absorption phenomenon to arise, leading to synergic effects of TPA and excited-state absorption and improved optical limitation behavior in the nanosecond regime. ${ }^{4,5}$

Until recently, optimization of molecular TPA has focused mainly on one-dimensional dipolar, ${ }^{6-12}$ or quadrupolar, $5,10,11,13-17$ structures. However, it has been realized lately that two-dimensional, ${ }^{18-20}$ branched $^{21-33}$ and $^{5}$ dendritic $^{29,32,34-37}$ structures could lead to highly effective multiphoton absorption. In this context, we have been interested in the elucidation of the role of dimensionality and charge-symmetry on molecular TPA. We have investigated a series of structurally-related chromophores of different symmetry (dipolar, quadrupolar, pseudo-dipolar, octupolar, dendritic...) and shape (rod-like, propeller-shaped, Y-shaped...). Their design is based on the functionalization of semirigid linear or branched conjugated backbones with electro-active (i.e. electron-releasing or electron-withdrawing) peripheral and core/node groups (Fig. 1). In addition to investigating structure-property relationships, our aim was to identify appropriate structural combinations to optimize the TPA/transparency/solubility/photostability trade-offs.

\footnotetext{
* mireille.blanchard-desce@univ-rennes1.fr; phone/fax: (33) 2 23236277; http://www.chimie.univ-rennes1.fr/umr/6510/index-en.htm
} 
Proc. SPIE 5516, Nonlinear Optical Transmission and Multiphoton Processes in Organics II, (15 October 2004); doi: 10.1117/12.559937

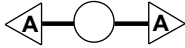

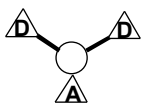<smiles>[Te]COC=[Te]</smiles><smiles>CC(Br)C(Br)Br</smiles><smiles></smiles><smiles>COC(OC(C)C)C(C)C</smiles>

D : electron-releasing moiety

A : electron-withdrawing moiety

— : conjugated connector

: core or node

D: peripheral groups

Fig. 1. Molecular engineering of multipolar chromophores for two-photon absorption and optical limitation.

The series includes quadrupolar molecules (Fig. 2) built from the symmetrical functionalization of a biphenyl core that is either free $\left(\mathbf{Q}_{1}, \mathbf{Q}_{2}\right)$ or planarized when using dinonylfluorene $\left(\mathbf{Q}_{\mathbf{3}}-\mathbf{Q}_{\mathbf{8}}\right)$. Quadrupolar chromophores bearing either electron-releasing $\left(\mathbf{Q}_{\mathbf{1}}-\mathbf{Q}_{4}\right)$ or electron-withdrawing $\left(\mathbf{Q}_{5}-\mathbf{Q}_{\mathbf{8}}\right)$ peripheral groups were investigated in order to assess the role of both end-groups on molecular two-photon absorptivity (Fig. 2). Arylene-vinylene and phenylene-ethynylene rods were used as connecting spacers between the core and the electroactive end-groups to ensure effective electronic conjugation while tuning the nonlinearity/transparency range.

All compounds show excellent solubility in apolar or weakly polar solvents (typically higher than 300 g.L $\mathrm{L}^{-1}$ ) due to the presence of the long alkyl chains on the core and/or the end-groups. This is of particular interest for optical limiting applications for which high concentrations are required. We also note that the linear nonyl chains $\left(n-\mathrm{C}_{9} \mathrm{H}_{19}\right)$ grafted on the fluorenyl core not only provide excellent solubility but also hamper tight $\pi$-stacking between chromophores in concentrated solution. ${ }^{38}$
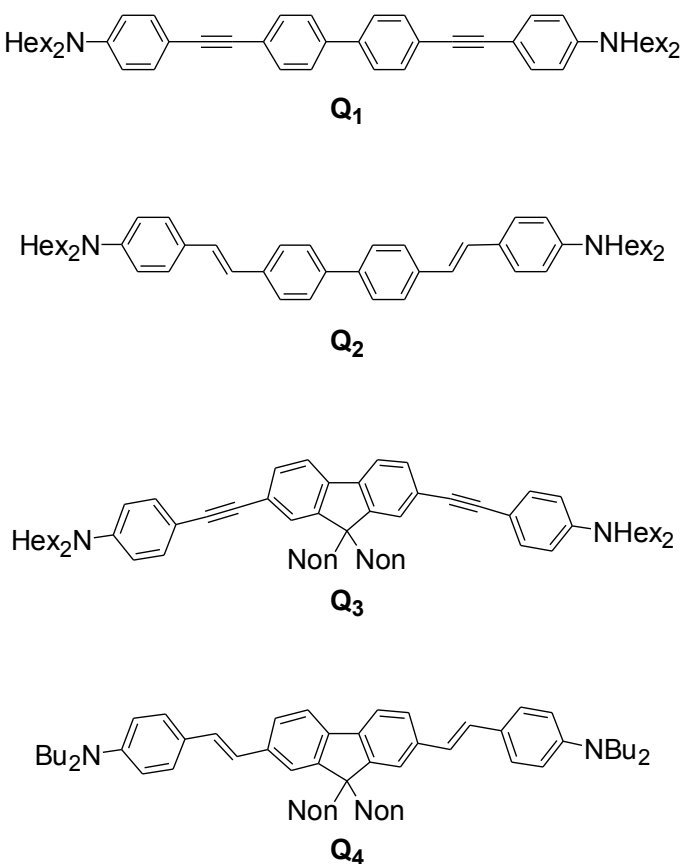
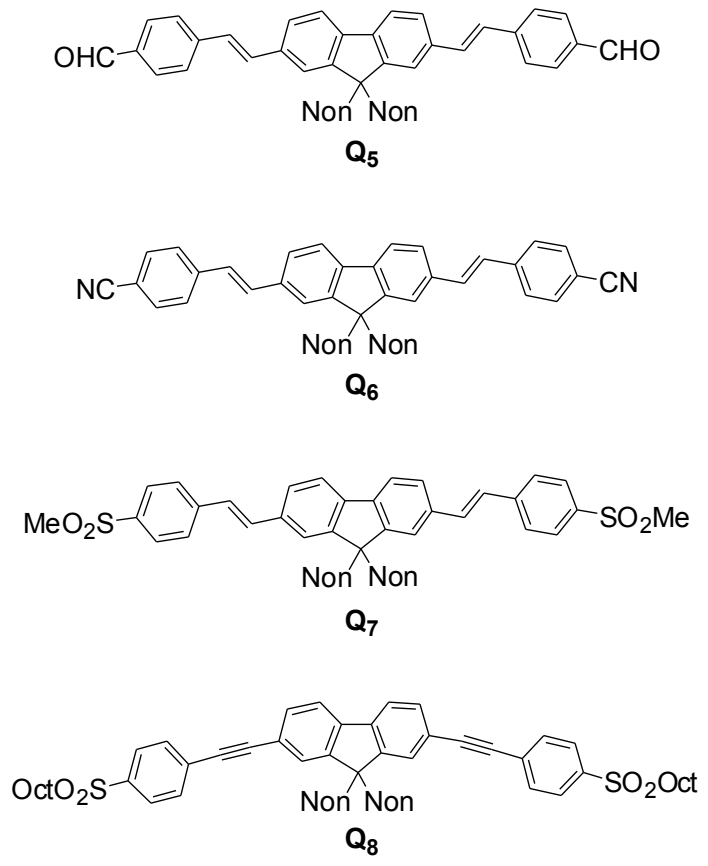

Fig. 2. Series of quadrupolar chromophores investigated in the present work. 
Proc. SPIE 5516, Nonlinear Optical Transmission and Multiphoton Processes in Organics II, (15 October 2004); doi: 10.1117/12.559937

Branched structures $\mathbf{T P B}_{\mathbf{1}}-\mathbf{T P B} \mathbf{B}_{3}$ where 1,3,5-triphenylbenzene (TPB) units (i.e. a trigonal analogue of the biphenyl core) are used as trigonal cores and nodes moieties (Fig. 3) have been studied in order to investigate branching and charge symmetry effects. In addition a branched structure $\mathbf{T P A}\left(\mathbf{Q}_{4}\right)$ built from the assembly of three chromophores $\mathbf{Q}_{4}$ via a common donating nitrogen has been investigated (Fig. 3).

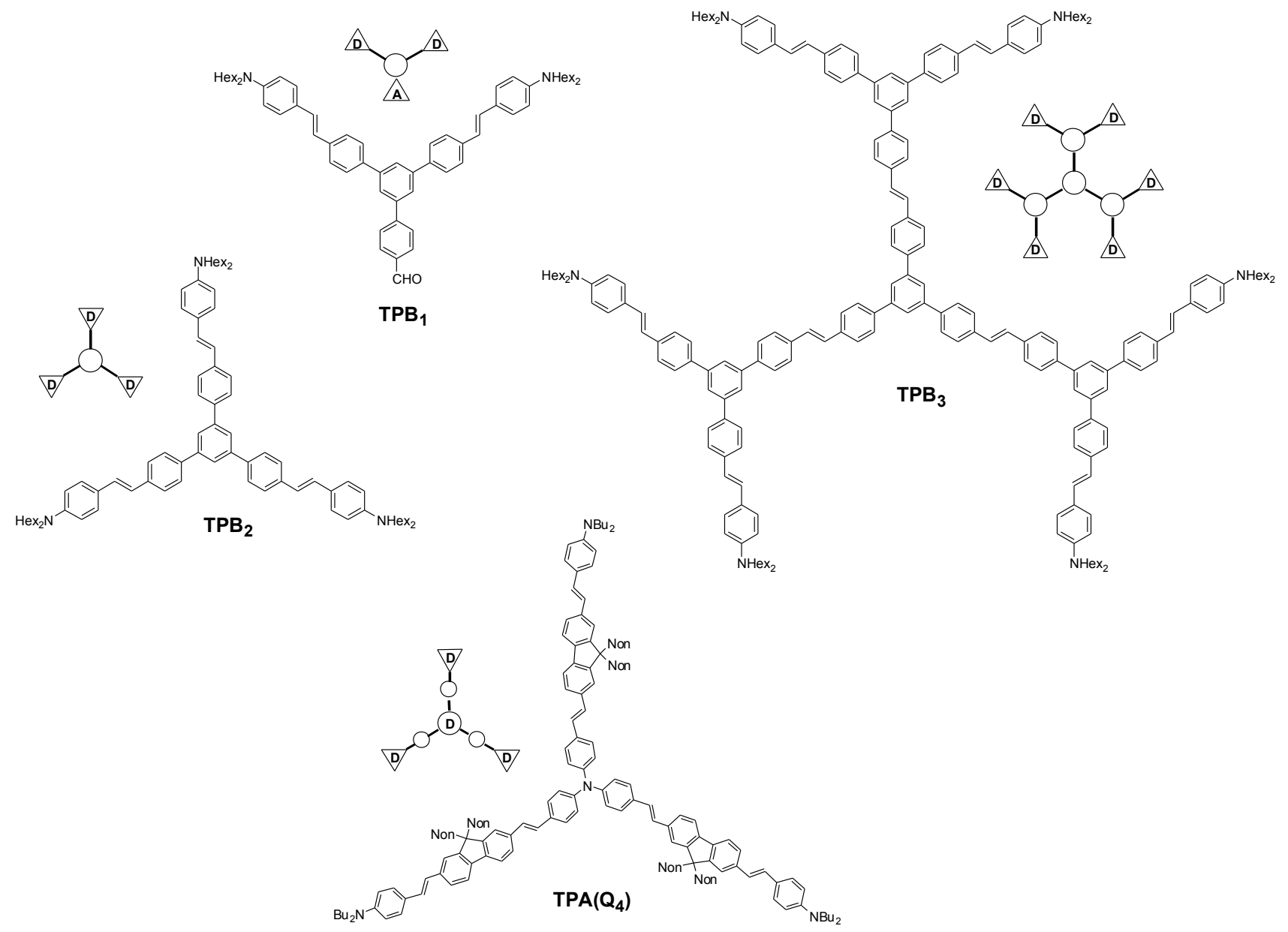

Fig. 3. Series of structurally-related branched chromophores built from triphenylbenzene (TPB) and triphenylamine (TPA) nodes.

\section{METHODOLOGY}

\subsection{Optical measurements}

UV/VIS spectra were recorded on a Jasco V-570 spectrophotometer.

Fluorescence measurements were performed at room temperature in diluted solutions (ca. $10^{-6} \mathrm{M}$ ) using a PTI spectrometer (LPS-220B) in photon counting mode. Emission spectra were obtained, for each compound, at $\lambda_{\mathrm{ex}}=$ $\lambda_{\max }(\mathrm{abs})$ with $\mathrm{A}_{\mathrm{ex}}=0.1$ to minimize internal absorption. Fluorescence quantum yields were measured on degassed samples at room temperature; fluorescein in $0.1 \mathrm{~N} \mathrm{NaOH}$ was used as a standard $\left(\Phi=0.90\right.$ at $\left.\lambda_{\mathrm{ex}}=470 \mathrm{~nm}\right)$ and refractive index correction was performed. ${ }^{39}$ The lifetime values were obtained from the reconvolution fit analysis of the decay profiles with the F900 analysis software and the fitting results were judged by the reduced chi-square value. 


\subsection{TPEF measurements}

The TPA cross-sections of the quadrupolar molecules were determined by investigating their TPEF properties. This procedure provides the TPEF action cross-sections $\sigma_{2} \Phi$ from which we can derive the corresponding $\sigma_{2}$ values. The TPEF excitation spectra of quadrupolar molecules were measured following the experimental protocol described in detail by $\mathrm{Xu}$ and $\mathrm{Webb},{ }^{40}$ using a mode-locked Ti:sapphire laser operating between 700 and $990 \mathrm{~nm}$ and delivering $80 \mathrm{fs}$ pulses at $80 \mathrm{MHz}$. TPEF measurements were calibrated relative to the absolute TPEF action cross-section determined by Xu and Webb for fluorescein in water $(\mathrm{pH}=11)$ in the $690-1050 \mathrm{~nm}$ range. ${ }^{40,41}$ The quadratic dependence of the fluorescence intensity on the excitation intensity was verified for every data point, indicating that the measurements were carried out in intensity regimes in which saturation or photodegradation do not occur. The experimental uncertainty is estimated to $\pm 10 \%$.

\subsection{Calculations}

Calculations and especially geometry optimization were conducted using the Gaussian 98 package ${ }^{42}$ with the $\mathrm{B}^{2} \mathrm{LYP}^{43}$ density functional and the $6-31 \mathrm{G}^{*}$ basis set. For the sake of simplicity, calculations have been conducted on chromophores where the alkyl solubilizing chains have been replaced by methyl substituents. Illustrations have been obtained with MOLEKEL. ${ }^{44}$

\section{RESULTS AND DISCUSSION}

The photophysical data of the chromophores are collected in Table 1.

Table 1. One and two-photon absorption properties of multipolar chromophores

\begin{tabular}{|c|c|c|c|c|c|c|c|c|c|c|}
\hline Compd & $X$ & Connector & Core/node & $\begin{array}{c}\lambda_{\max } \text { OPA } \\
(\mathrm{nm})\end{array}$ & $\begin{array}{r}\lambda_{\text {cut-off }}{ }^{a} \\
(\mathrm{~nm})\end{array}$ & $\begin{array}{c}\tau^{b} \\
\text { (ns) }\end{array}$ & $\begin{array}{l}\lambda_{\mathrm{TPA}} \\
(\mathrm{nm})\end{array}$ & $\begin{array}{c}\sigma_{2}^{c} \\
(\mathrm{GM})\end{array}$ & $\mathrm{N}^{d}$ & $\sigma_{2} / \mathrm{N}^{2 e}$ \\
\hline $\mathbf{Q}_{1}$ & $\mathrm{NHex}_{2}$ & PE & BP & 374 & 422 & 0.70 & 705 & 890 & 28 & 1.14 \\
\hline $\mathbf{Q}_{2}$ & $\mathrm{NHex}_{2}$ & PV & BP & 401 & 455 & 0.82 & 730 & 1040 & 28 & 1.33 \\
\hline $\mathbf{Q}_{3}$ & $\mathrm{NHex}_{2}$ & PE & FL & 387 & 436 & 0.74 & 705 & 1200 & 28 & 1.53 \\
\hline $\mathbf{Q}_{4}$ & $\mathrm{NBu}_{2}$ & PV & FL & 415 & 465 & 0.87 & 740 & 1265 & 28 & 1.61 \\
\hline $\mathbf{Q}_{5}$ & $\mathrm{CHO}$ & PV & FL & 397 & 447 & 0.86 & 705 & 575 & 32 & 0.56 \\
\hline $\mathbf{Q}_{6}$ & $\mathrm{CN}$ & PV & FL & 389 & 434 & 0.84 & 705 & 395 & 32 & 0.39 \\
\hline $\mathbf{Q}_{7}$ & $\mathrm{SO}_{2} \mathrm{Me}$ & PV & FL & 387 & 429 & 0.87 & 705 & 215 & 32 & 0.21 \\
\hline $\mathbf{Q}_{8}$ & $\mathrm{SO}_{2} \mathrm{Oct}$ & PE & FL & 363 & 411 & 0.64 & 705 & 52 & 32 & 0.05 \\
\hline $\mathbf{T P B}_{1}$ & $\mathrm{NHex}_{2} / \mathrm{CHO}$ & $\mathrm{PV} /-$ & ТРB & 385 & 436 & 0.79 & 755 & 365 & 24.25 & 0.62 \\
\hline $\mathbf{T P B}_{2}$ & $\mathrm{NHex}_{2}$ & PV & ТРВ & 384 & 433 & 0.63 & 735 & 530 & 28.14 & 0.67 \\
\hline $\mathbf{T P B}_{3}$ & $\mathrm{NHex}_{2}-\mathrm{PV}$ & TPB-V & ТРВ & 375 & 432 & 0.60 & 755 & 810 & 50.79 & 0.31 \\
\hline $\operatorname{TPA}\left(\mathbf{Q}_{4}\right)$ & $\mathrm{NBu}_{2}$ & V-FIV & TPA & 428 & 480 & 0.85 & 735 & 4160 & 48.5 & 1.77 \\
\hline
\end{tabular}

${ }^{a} \lambda$ at which the transmittance is $95 \% .{ }^{b}$ Experimental fluorescence lifetime from time-correlated single photon counting experiments. ${ }^{c}$ TPA cross-sections at $\lambda_{\text {TPA }} ; 1 \mathrm{GM}=10^{-50} \mathrm{~cm}^{4}$.s.photon; TPEF measurements were performed using a mode-locked Ti:sapphire laser delivering $80 \mathrm{fs}$ pulses at $80 \mathrm{MHz}$, calibrating with fluorescein. ${ }^{d}$ Effective number $\mathrm{N}$ of $\pi$-electrons in the conjugated system. ${ }^{45 e}{ }^{e} \mathrm{TPA}$ cross-sections at $\lambda_{\text {TPA }}$ normalized by $\mathrm{N}^{2}$.

\subsection{Structure-property relationships in quadrupoles}

\subsubsection{End-groups' effect}

As noted from Table 1 and illustrated in Fig. $4\left(\mathbf{Q}_{3}, \mathbf{Q}_{8}\right)$ and Fig. $5\left(\mathbf{Q}_{4}, \mathbf{Q}_{5}\right)$, push-push chromophores always show larger TPA cross-sections in the NIR region than corresponding pull-pull derivatives, in correlation with a definite 
Proc. SPIE 5516, Nonlinear Optical Transmission and Multiphoton Processes in Organics II, (15 October 2004); doi: 10.1117/12.559937

red shift of the one-photon absorption spectra. Push-push derivatives thus offer interesting potentialities for optical limitation in the red-near IR region.

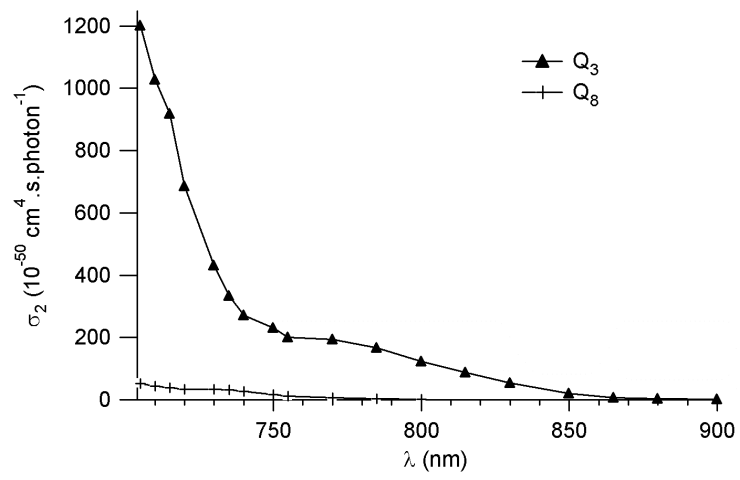

Fig. 4. TPA spectra of fluorophores $\mathbf{Q}_{3}$ and $\mathbf{Q}_{\mathbf{8}}$ in toluene.

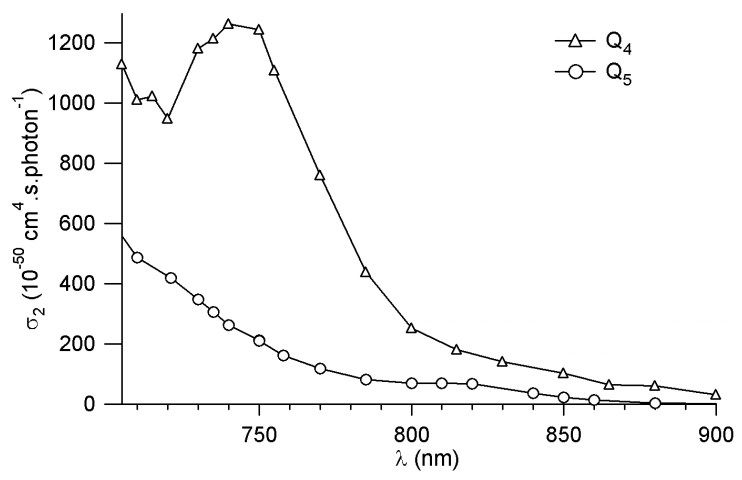

Fig. 5. TPA spectra of fluorophores $\mathbf{Q}_{4}$ and $\mathbf{Q}_{5}$ in toluene.

Indeed numerical simulations performed with compounds $\mathbf{Q}_{\mathbf{1}}$ and $\mathbf{Q}_{\mathbf{2}}$ (which also exhibit an intense excited-state absorption band overlapping the two-photon absorption band in the red-NIR region) demonstrate a strong nonlinear absorption behavior, suitable for optical limiting of nanosecond pulses (with threshold values down to $1.5 \times 10^{-2} \mathrm{~J}_{\mathrm{cm}}^{-2}$ for 0.55 ns pulses $){ }^{17}$

Comparison of pull-pull derivatives $\mathbf{Q}_{5}-\mathbf{Q}_{7}$ (Fig. 6 and Table 1) indicates that increasing the electronwithdrawing strength of the end-groups ( $\left.\mathrm{CHO}: \sigma_{p}=0.42, \mathrm{CN}: \sigma_{p}=0.66, \mathrm{SO}_{2} \mathrm{Me}: \sigma_{p}=0.72\right)^{46}$ results in a decrease of the TPA cross-section in the NIR region. Since pull-pull compounds are blue-shifted as compared to push-push derivatives, pull-pull derivatives offer a promising alternative for optical limiting in the visible blue region.

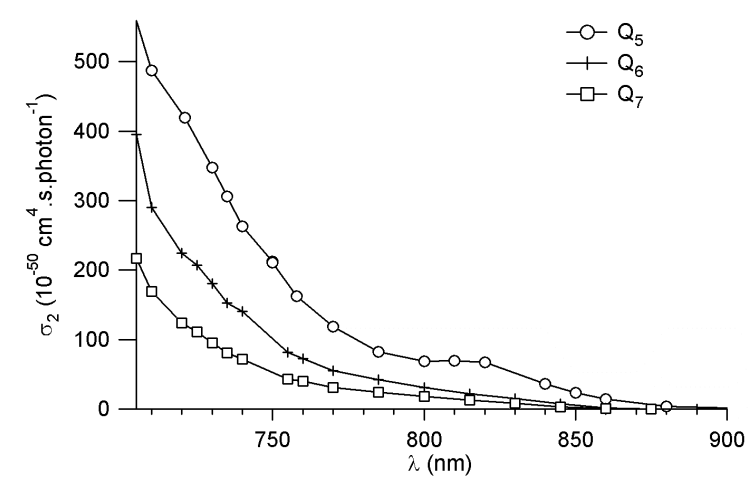

Fig. 6. TPA spectra of fluorophores $\mathbf{Q}_{5}-\mathbf{Q}_{7}$ in toluene.

\subsubsection{Core effect}

Comparison of push-push derivatives built from different core moieties and bearing similar end-groups demonstrates that the nature of conjugated core significantly influences the TPA spectra. 

Organics II, (15 October 2004); doi: 10.1117/12.559937
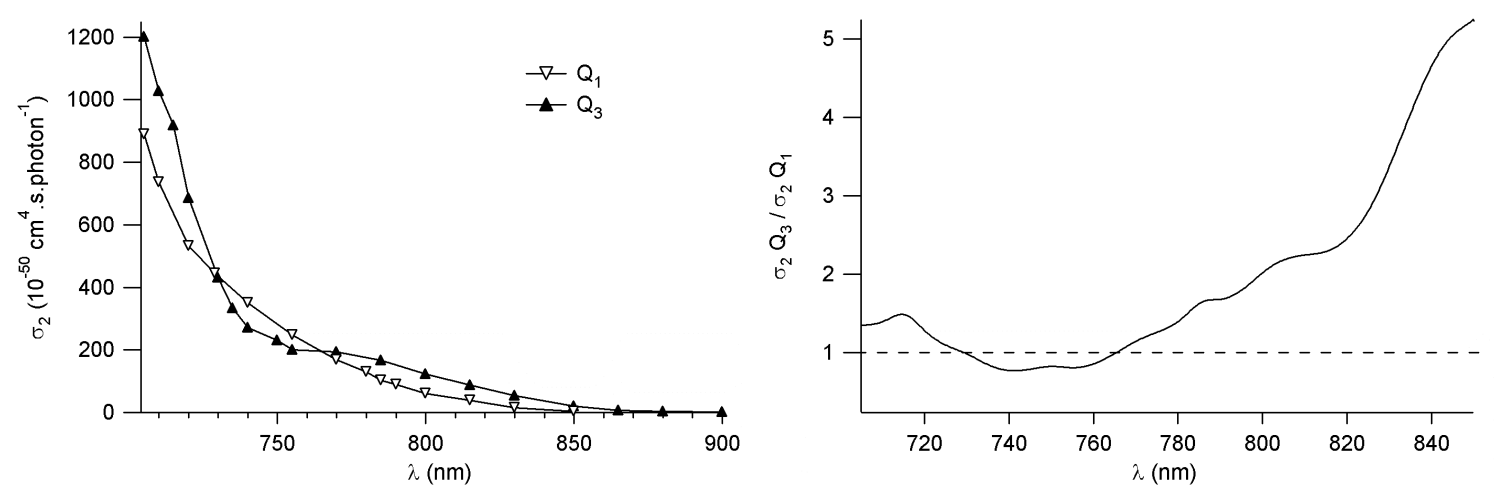

Fig. 7. TPA spectra of fluorophores $\mathbf{Q}_{1}$ and $\mathbf{Q}_{3}$ in toluene.

From Fig. 7 (left) and Table 1, we observe that replacing the twisted biphenyl core (BP) by the planarized fluorene unit (Fl) results in both a red shift and a significant enhancement of the TPA cross-section close to the red region. In addition we observe that chromophore $\mathbf{Q}_{3}$ shows a low energy TPA maximum at $774 \mathrm{~nm}\left(\right.$ i.e. at $\left.2 \lambda_{\max }{ }^{\text {OPA }}\right)$. This indicates that the lowest excited state is both one-photon and two-photon allowed in the case of chromophore $\mathbf{Q}_{3}$. Such phenomenon is not observed in the case of chromophore $\mathbf{Q}_{\mathbf{1}}$ and is most probably related to the slight loss of symmetry caused by the fluorenyl moiety as compared to the symmetrical biphenyl unit. Such effect is responsible for the much more pronounced TPA efficiency in the NIR region (at $\lambda>800 \mathrm{~nm}$ ) as illustrated in Fig. 7 (right).

\subsubsection{Linker effect}

As observed from the comparison of homologous push-push derivatives $\mathbf{Q}_{\mathbf{1}}$ and $\mathbf{Q}_{\mathbf{2}}$, replacing a phenyleneethynylene linker (PE) by a phenylene-vinylene one (PV) leads to larger TPA cross-sections in the 720-900 nm range (Fig. 8), in relation with a bathochromic shift of the TPA band. This effect is also visible when comparing the homologous PE and PV pull-pull derivatives $\mathbf{Q}_{\mathbf{8}}$ and $\mathbf{Q}_{7}$ (Fig. 9). However, for push-push derivatives, the TPA crosssection become comparable close the red region (see for instance compounds $\mathbf{Q}_{3}$ and $\mathbf{Q}_{4}$ in Table 1).

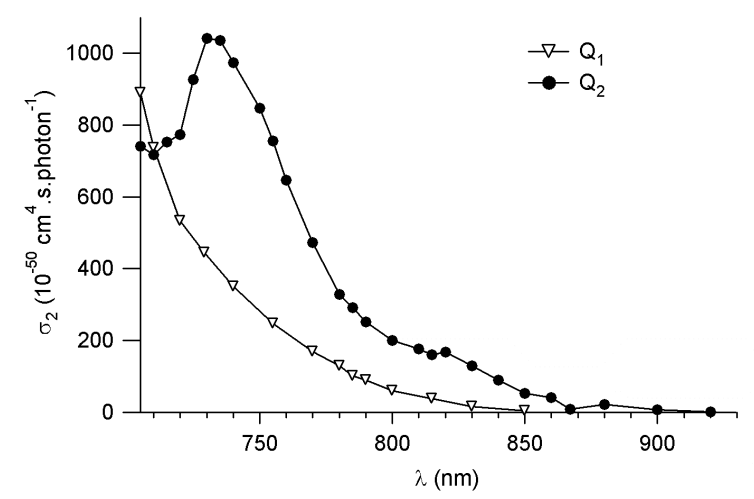

Fig. 8. TPA spectra of fluorophores $\mathbf{Q}_{\mathbf{1}}-\mathbf{Q}_{\mathbf{2}}$ in toluene.

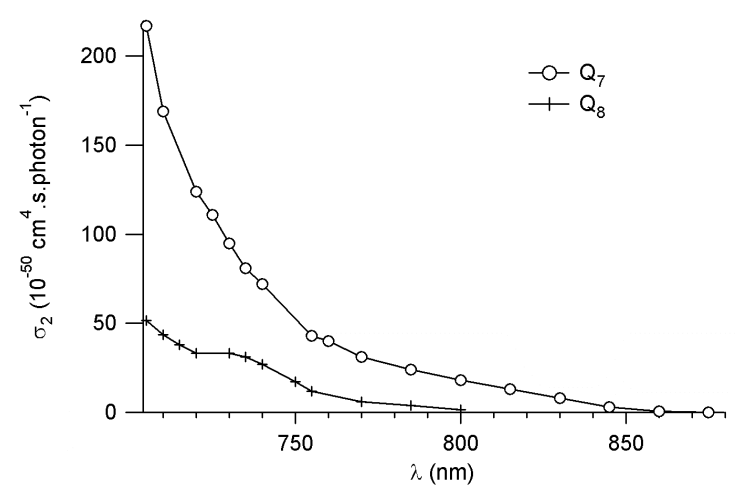

Fig. 9. TPA spectra of fluorophores $\mathbf{Q}_{7}-\mathbf{Q}_{8}$ in toluene.

Moreover, the use of PE linkers lead to higher transparency in the visible range, as well as improved photostability (due to the lack of photoisomerization), as indicated by the absence of photodegradation either upon pulsed-laser or prolonged lamp irradiation. ${ }^{14,31}$ In view of their improved nonlinearity/transparency/stability trade-off, push-push derivatives with PE linkers thus represent interesting candidates for optical power limitation in the visible region. 


\subsection{Branching effect}

Recently following pioneering work by P. N. Prasad and coll., several experimental and theoretical ${ }^{47}$ studies $^{4}$ have focused on the effect of branching on TPA. These studies lead to different outcomes: cooperative enhancement, $^{22,28,35,36}$, additive behavior ${ }^{24,34}$ or even decrease of TPA. ${ }^{22}$ It should be emphasized that these results were obtained, in most cases, at one single wavelength, which might explain the different conclusions. In that context, we have been interested in investigating the wavelength dependence of the branching effect in various types of multipolar branched systems. Our goal was both to identify the origin of the discrepancies, and to assess the influence of charge symmetry. Indeed, a number of factors influence the TPA magnitude, such as electronic delocalization and intramolecular charge transfer phenomena, symmetry and dimensionality. A correlation between the square of the number of $\pi$-electrons in the conjugated systems $(\mathrm{N})$ and the maximum TPA that can be reached has been reported recently. ${ }^{45}$

\subsubsection{Branching of quadrupoles}

In this perspective, comparison of the TPA spectra of quadrupolar chromophores $\mathbf{Q}_{\mathbf{4}}$ and its three-branched analogue $\mathbf{T P A}\left(\mathbf{Q}_{4}\right)$ is quite informative. First of all, chromophore $\mathbf{T P A}\left(\mathbf{Q}_{4}\right)$ exhibits a larger normalized maximum TPA cross-sections $\left(\sigma_{2} / N^{2}\right)$ than its quadrupolar branch $\mathbf{Q}_{4}$ (Table 1) and one of the highest measured in the femtosecond regime for a branched structure. ${ }^{28}$ In addition it maintains similar excited-state lifetime. These features are important for optical power limiting in the nanosecond regime since excited-state absorption subsequent to two-photon excitation is known to be responsible for the strongly nonlinear absorption behavior of quadrupolar chromophores. ${ }^{4,17}$

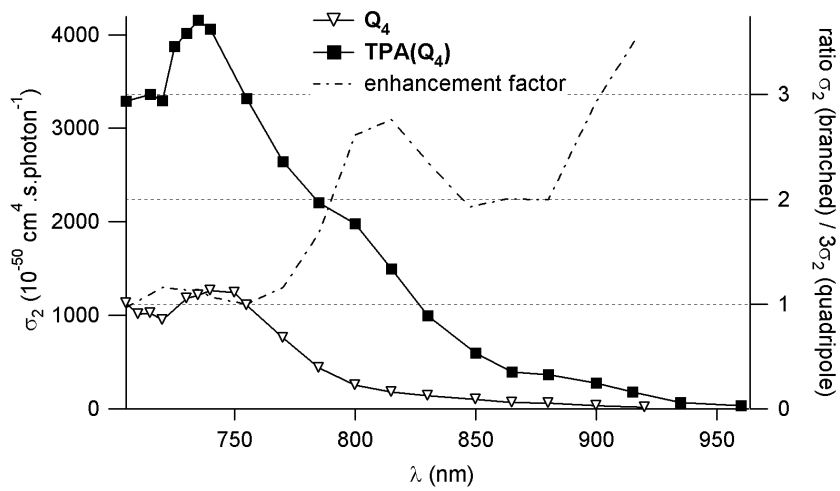

Fig. 10. Effect of branching of quadrupoles on TPA.

In addition, the ratio between the TPA cross-sections of quadrupolar chromophore $\mathbf{Q}_{4}$ and its three-branched derivative $\mathbf{T P A}\left(\mathbf{Q}_{4}\right)$ significantly depends on the wavelength (Fig. 10). At lower wavelength, the contribution of the three quadrupolar branches to the TPA amplitude of $\mathbf{T P A}\left(\mathbf{Q}_{4}\right)$ seems roughly additive. The ratio significantly increases at higher wavelength, branched chromophore $\operatorname{TPA}\left(\mathbf{Q}_{4}\right)$ overcoming chromophore $\mathbf{Q}_{4}$. This effect is correlated with a definite TPA spectral broadening further to the NIR region where new TPA bands appear to emerge. Such phenomenon might be originating from an electronic coupling between the quadrupolar branches via the TPA core. In that respect, we note from Table 1 that the one-photon absorption band of $\mathbf{T P A}\left(\mathbf{Q}_{4}\right)$ is red-shifted with respect to that of chromophore $\mathbf{Q}_{4}$, suggesting that such coupling takes place.

\subsubsection{Influence of charge symmetry and branched character}

The series of structurally-related multipolar chromophores $-\mathbf{Q}_{\mathbf{2}}$ (quadrupolar), $\mathbf{T} \mathbf{P} \mathbf{B}_{1}$ (pseudo-dipolar), $\mathbf{T} \mathbf{P} \mathbf{B}_{2}$ (octupolar) and $\mathbf{T P B}_{3}$ (dendritic) - built from the (linear) biphenyl or (trigonal) triphenylbenzene core/nodes was examined in order to investigate both the role of branching and charge symmetry. HOMO-LUMO calculations reveal that multipolar derivatives show pronounced intramolecular charge transfer phenomena upon excitation (Fig. 11-13). A charge density shift from the electron-releasing peripheral groups to the biphenyl $\left(\mathbf{Q}_{2}\right)$ or triphenylbenzene $\left(\mathbf{T} \mathbf{P B} \mathbf{B}_{2}\right)$ core is observed both in 1-D quadrupolar chromophore $\mathbf{Q}_{2}$ and in 2-D octupolar chromophore $\mathbf{T} \mathbf{P B}$. For Y-shaped pseudo- 
Proc. SPIE 5516, Nonlinear Optical Transmission and Multiphoton Processes in Organics II, (15 October 2004); doi: 10.1117/12.559937

dipolar chromophore $\mathbf{T} \mathbf{P B}_{1}$, a directional intramolecular charge transfer from the donating end-groups towards the acceptor moiety is observed even though the donating and accepting moieties are not conjugated.

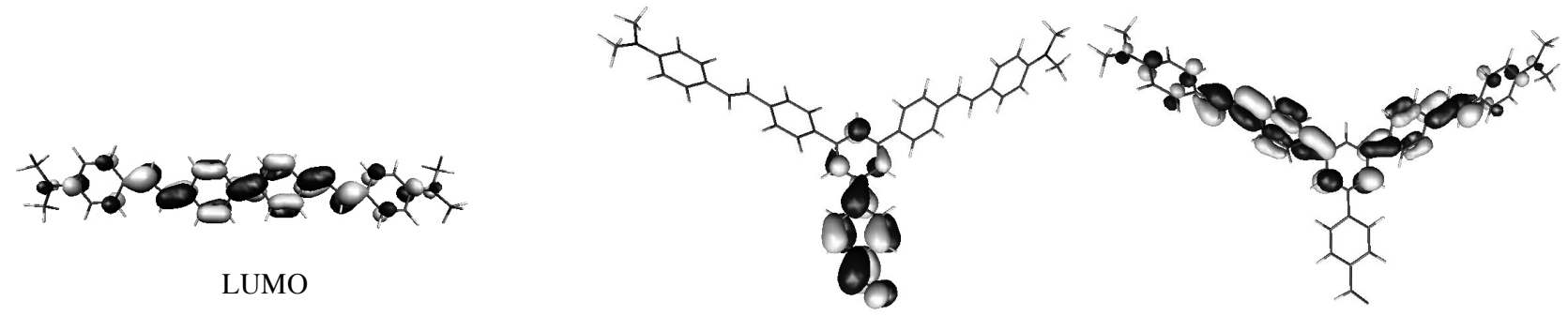

LUMO

LUMO+1

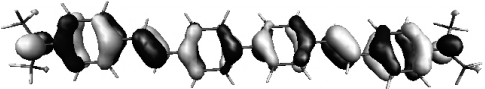

HOMO

Fig. 11. Frontier orbitals of $\mathbf{Q}_{2}$.

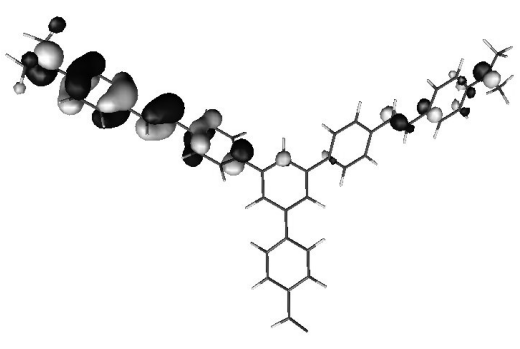

HOMO-1

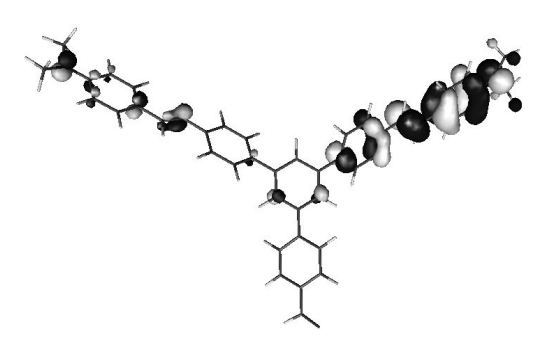

HOMO

Fig.12. Frontier orbitals of $\mathbf{T P B}_{\mathbf{1}}$.
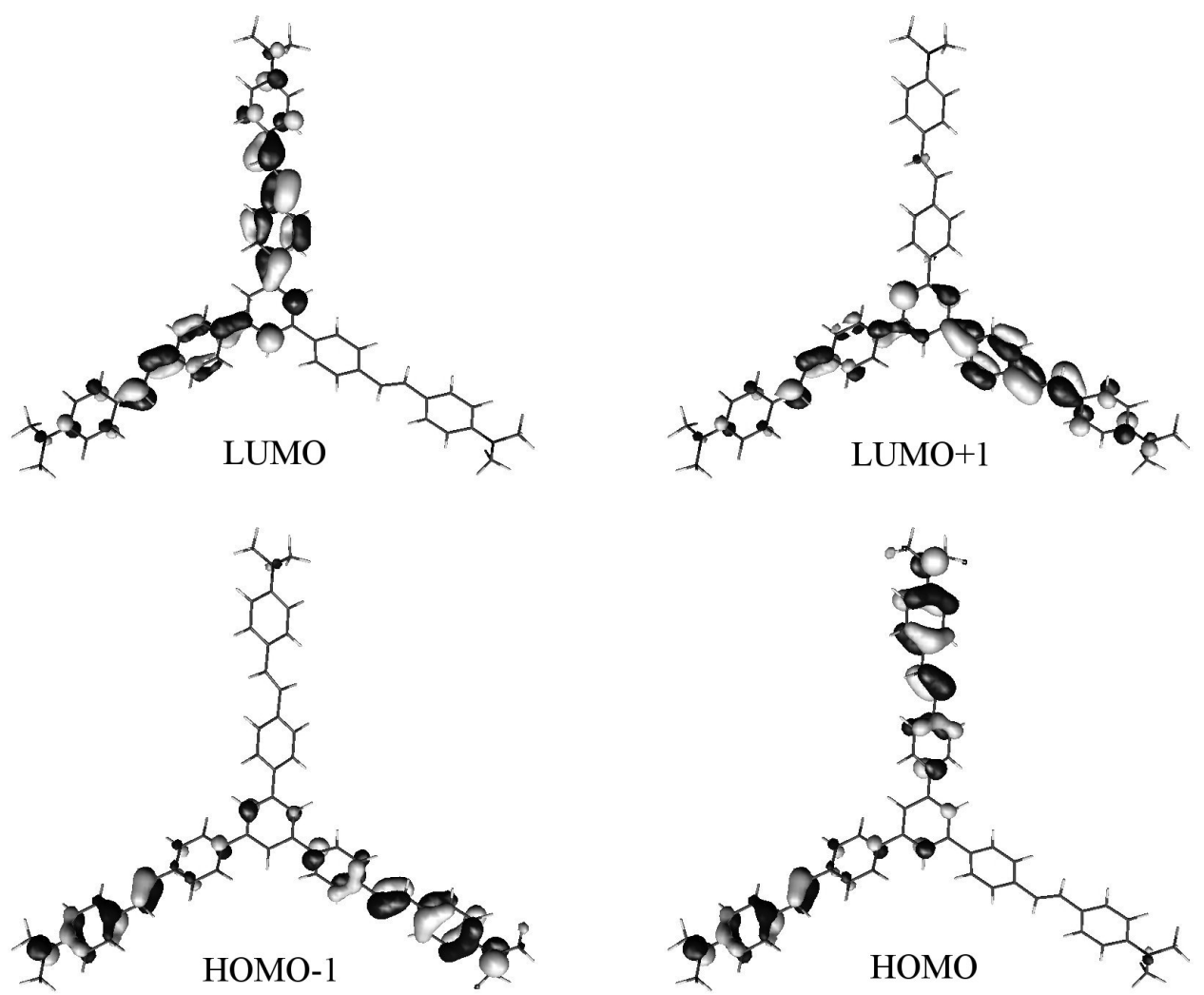

Fig.13. Frontier orbitals of $\mathbf{T P B}_{2}$. 
Interestingly, we observe from Table 1 and Fig. 14 that increasing the branched character leads to improved transparency: a clear blue-shift of the absorption band is observed with increasing number of branches in the chromophores. As a result branched chromophores $\mathbf{T} \mathbf{P} \mathbf{B}_{\mathbf{1}}-\mathbf{T} \mathbf{P} \mathbf{B}_{3}$ retain wide transparency in the visible region.

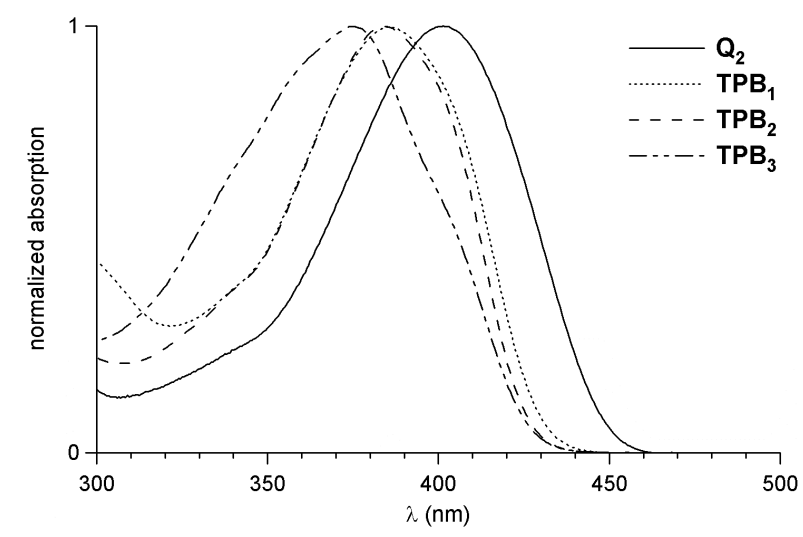

Fig. 14. Normalized absorption spectra of $\mathbf{Q}_{2}$ and $\mathbf{T} \mathbf{P} \mathbf{B}_{1}-\mathbf{T} \mathbf{P} \mathbf{B}_{3}$ in toluene.

We observe from Fig. 15 that the 1-D quadrupolar chromophore $\mathbf{Q}_{\mathbf{2}}$ shows the highest TPA cross-section close to the visible red while all 2-D branched structures become more efficient two-photon absorbers at $\lambda>780 \mathrm{~nm}$. Indeed the branched structures show broader and red-shifted TPA band in the NIR region. Hence, the branched-structures exhibit both improved transparency in the visible region (as a result of a blue-shift of the OPA bands) and superior TPA efficiency further to the NIR region as compared their 1D-quadrupolar analogue (as a result of a red-shift of the TPA bands). For instance, the dendritic chromophore $\mathbf{T P B}_{3}$ shows a three times larger TPA cross-section at $800 \mathrm{~nm}$ than chromophore $\mathbf{Q}_{\mathbf{2}}$ while being more transparent (Table 1). Hence increasing the branched character in multipolar structures built from the triphenylbenzene core seems to be a promising route for improving the TPA-transparency tradeoff in the context of broadband optical limitation in the NIR region.
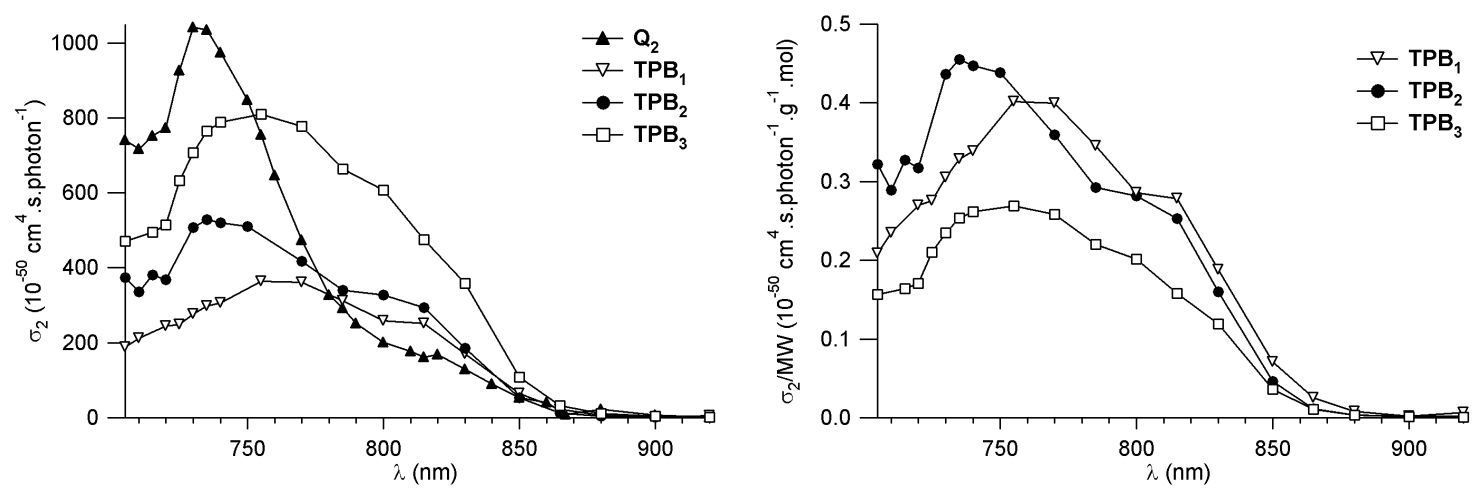

Fig. 15. Effect of branching on TPA in multipolar structures built from TPB core/nodes.

To compare the efficiency of the various branched structure in view of optical power limiting, it is helpful to consider the normalized TPA molecular efficiency $\sigma_{2} / \mathrm{MW}$ (Fig. 15 right). Interestingly, in the NIR region both the twobranched pseudo-dipolar chromophore $\mathbf{T P B}_{\mathbf{1}}$ and the three-branched octupolar chromophore $\mathbf{T} \mathbf{P} \mathbf{B}_{\mathbf{2}}$ appear as the best candidates in terms of normalized TPA-transparency trade-off. On the other hand, comparison of the normalized TPA efficiency of octupolar chromophore $\mathbf{T P B}_{\mathbf{2}}$ and of its second-generation dendritic analogue $\mathbf{T} \mathbf{P} \mathbf{B}_{\mathbf{3}}$ shows that in that particular case, increased branching character does not bring a net gain in normalized TPA efficiency (Fig. 15). This is most likely related to more confined intramolecular charge transfer phenomena in dendritic structures like $\mathbf{T P B}_{\mathbf{3}}$, as compared to pseudo-dipolar and octupolar structures $\left(\mathbf{T P B} \mathbf{B}_{\mathbf{1}}\right.$ and $\left.\mathbf{T P B} \mathbf{B}_{\mathbf{2}}\right)$. 


\section{Proc. SPIE 5516, Nonlinear Optical Transmission and Multiphoton Processes in Organics II, (15 October 2004); doi: 10.1117/12.559937}

\section{CONCLUSION}

The present work shows that modulation of the nonlinear absorptivity/transparency/photostability trade-off in 1D-quadupolar structures can be achieved by playing on both core and spacer structures. In particular, the replacement of the double bond by a triple bond in the conjugated spacers in push-push derivatives yields optimized TPA/transparency/photostability features for optical power limiting in the visible red region. In contrast, pull-pull derivatives are good candidates for optical power limiting in the visible blue. Both push-push and pull-pull quadrupolar chromophores also display very high solubility in apolar or weakly polar solvents. Such behavior is particularly attractive in the context of the search for optimizing multiphoton absorbers for broadband optical power limitation. Indeed nonlinear transmission experiments in the visible region conducted in solution in the nanosecond regime yield similar structure-TPA relationships as those derived from TPEF measurements in the NIR, and indicate that quadrupoles $\mathbf{Q}_{1}-\mathbf{Q}_{4}$ show pronounced optical limiting properties. ${ }^{48}$

The present study also demonstrates that the branching strategy provides a useful route for TPA enhancement and/or spectral broadening in the NIR region. In addition, by playing on the nature of the core/nodes and the charge symmetry, the transparency/nonlinearity trade-off can be tuned via control of the intramolecular charge transfer phenomena.

\section{ACKNOWLEDGEMENTS}

This work was supported in part by the Centre National de la Recherche Scientifique and Rennes Métropole. M. C. received a fellowship from the Direction Générale pour l'Armement and L. P. a fellowship from the Ministère de l'Education Nationale, de l'Enseignement Supérieur et de la Recherche. We also wish to thank M. H. V. Werts for important help in TPEF experiments. Calculations were supported by the "Centre Informatique National de l'Enseignement Supérieur" (CINES-France).

\section{REFERENCES}

1. G. S. He, G. C. Xu, P. N. Prasad, B. A. Reinhardt, J. C. Bhatt, R. McKellar and A. G. Dillard, "Two-photon absorption and optical-limiting properties of novel organic compounds", Opt. Lett. 20, 435-437, 1995.

2. G. S. He, J. D. Bhawalkar, C. F. Zhao and P. N. Prasad, "Optical limiting effect in a two-photon absorption dye doped solid matrix", Appl. Phys. Lett. 67, 2433-2435, 1995.

3. J. E. Ehrlich, X. L. Wu, I. Y. S. Lee, Z. Y. Hu, H. Röckel, S. R. Marder and J. W. Perry, "Two-photon absorption and broadband optical limiting with bis-donor stilbenes", Opt. Lett. 22, 1843-1845, 1997.

4. J. W. Perry, S. Barlow, J. E. Ehrlich, A. A. Heikal, Z. Y. Hu, I. Y. Lee, K. Mansour, S. R. Marder, H. Röckel, M. Rumi, S. Thayumanavan and X. L. Wu, "Two-photon and higher-order absorptions and optical limiting properties of bis-donor substituted conjugated organic chromophores", MCLC S\&T, Section B: Nonlinear Optics 21, 225-243, 1999.

5. M. Albota, D. Beljonne, J.-L. Brédas, J. E. Ehrlich, J.-Y. Fu, A. A. Heikal, S. E. Hess, T. Kogej, M. D. Levin, S. R. Marder, D. McCord-Maughon, J. W. Perry, H. Röckel, M. Rumi, G. Subramaniam, W. W. Webb, X.-L. $\mathrm{Wu}$ and $\mathrm{C} . \mathrm{Xu}$, "Design of organic molecules with large two-photon absorption cross sections", Science 281, 1653-1656, 1998.

6. G. S. He, L. Yuan, N. Cheng, J. D. Bhawalkar, P. N. Prasad, L. L. Brott, S. J. Clarson and B. A. Reinhardt, "Nonlinear optical properties of a new chromophore", J. Opt. Soc. Am. B 14, 1079-1087, 1997.

7. B. A. Reinhardt, L. L. Brott, S. J. Clarson, A. G. Dillard, J. C. Bhatt, R. Kannan, L. Yuan, G. S. He and P. N. Prasad, "Highly active two-photon dyes: design, synthesis, and characterization toward application", Chem. Mater. 10, 1863-1874, 1998.

8. L. Ventelon, M. Blanchard-Desce, L. Moreaux and J. Mertz, "New quadrupolar fluorophores with high twophoton excited fluorescence", Chem. Commun., 2055-2056, 1999.

9. K. D. Belfield, D. J. Hagan, E. W. Van Stryland, K. J. Schafer and R. A. Negres, "New Two-Photon Absorbing Fluorene Derivatives: Synthesis and Nonlinear Optical Characterization", Org. Lett. 1, 1575-1578, 1999. 
10. O.-K. Kim, K.-S. Lee, H. Y. Woo, K.-S. Kim, G. S. He, S. H. Guang, J. Swiatkiewicz and P. N. Prasad, "New Class of Two-Photon-Absorbing Chromophores Based on Dithienothiophene", Chem. Mater. 12, 284-286, 2000 .

11. B. Strehmel, A. M. Sarker and H. Detert, "The influence of $\sigma$ and $\pi$ acceptors on two-photon absorption and solvatochromism of dipolar and quadrupolar unsaturated organic compounds", ChemPhysChem 4, 249-259, 2003.

12. L. Antonov, K. Kamada, K. Ohta and F. S. Kamounah, "A systematic femtosecond study on the two-photon absorbing D- $\pi$-A molecules- $\pi$-bridge nitrogen insertion and strength of the donor and acceptor groups", Phys. Chem. Chem. Phys. 5, 1193-1197, 2003.

13. L. Ventelon, S. Charier, L. Moreaux, J. Mertz and M. Blanchard-Desce, "Nanoscale push-push dihydrophenanthrene derivatives as novel fluorophores for two-photon-excited fluorescence", Angew. Chem., Int. Ed. 40, 2098-2101, 2001.

14. O. Mongin, L. Porrès, L. Moreaux, J. Mertz and M. Blanchard-Desce, "Synthesis and Photophysical Properties of New Conjugated Fluorophores Designed for Two-Photon-Excited Fluorescence", Org. Lett. 4, 719-722, 2002.

15. A. Abbotto, L. Beverina, R. Bozio, A. Facchetti, C. Ferrante, G. A. Pagani, D. Pedron and R. Signorini, "Novel Heterocycle-Based Two-Photon Absorbing Dyes", Org. Lett. 4, 1495-1498, 2002.

16. Y. Iwase, K. Kamada, K. Ohta and K. Kondo, "Synthesis and photophysical properties of new two-photon absorption chromophores containing a diacetylene moiety as the central $\pi$-bridge", J. Mater. Chem. 13, 1575 1581, 2003.

17. M. G. Silly, L. Porrès, O. Mongin, P.-A. Chollet and M. Blanchard-Desce, "Optical limiting in the red-NIR range with soluble two-photon absorbing molecules", Chem. Phys. Lett. 379, 74-80, 2003.

18. M. Drobizhev, A. Karotki, M. Kruk, N. Z. Mamardashvili and A. Rebane, "Drastic enhancement of two-photon absorption in porphyrins associated with symmetrical electron-accepting substitution", Chem. Phys. Lett. 361, 504-512, 2002.

19. M. Drobizhev, A. Karotki, M. Kruk and A. Rebane, "Resonance enhancement of two-photon absorption in porphyrins", Chem. Phys. Lett. 355, 175-182, 2002.

20. O. S. Pyun, W. Yang, M.-Y. Jeong, S. H. Lee, K. M. Kang, S.-J. Jeon and B. R. Cho, "Synthesis and twophoton absorption property of phenylacetylene macrocycles", Tetrahedron Lett. 44, 5179-5182, 2003.

21. M. P. Joshi, J. Swiatkiewicz, F. Xu, P. N. Prasad, B. A. Reinhardt and R. Kannan, "Energy transfer coupling of two-photon absorption and reverse saturable absorption for enhanced optical power limiting", Opt. Lett. 23, 1742-1744, 1998.

22. S.-J. Chung, K.-S. Kim, T.-C. Lin, G. S. He, J. Swiatkiewicz and P. N. Prasad, "Cooperative Enhancement of Two-Photon Absorption in Multi-branched Structures", J. Phys. Chem. B 103, 10741-10745, 1999.

23. G. S. He, J. Swiatkiewicz, Y. Jiang, P. N. Prasad, B. A. Reinhardt, L.-S. Tan and R. Kannan, "Two-Photon Excitation and Optical Spatial-Profile Reshaping via a Nonlinear Absorbing Medium", J. Phys. Chem. A 104, 4805-4810, 2000.

24. S.-J. Chung, T.-C. Lin, K.-S. Kim, G. S. He, J. Swiatkiewicz, P. N. Prasad, G. A. Baker and F. V. Bright, "TwoPhoton Absorption and Excited-State Energy-Transfer Properties of a New Multibranched Molecule", Chem. Mater. 13, 4071-4076, 2001.

25. B. R. Cho, K. H. Son, H. L. Sang, Y.-S. Song, Y.-K. Lee, S.-J. Jeon, J. H. Choi, H. Lee and M. Cho, "Two Photon Absorption Properties of 1,3,5-Tricyano-2,4,6-tris(styryl)benzene Derivatives", J. Am. Chem. Soc. 123, 10039-10045, 2001.

26. D. Beljonne, W. Wenseleers, E. Zojer, Z. Shuai, H. Vogel, S. J. K. Pond, J. W. Perry, S. R. Marder and J.-L. Brédas, "Role of dimensionality on the two-photon absorption response of conjugated molecules: the case of octupolar compounds", Adv. Funct. Mater. 12, 631-641, 2002.

27. J. Yoo, S. K. Yang, M.-Y. Jeong, H. C. Ahn, S.-J. Jeon and B. R. Cho, "Bis-1,4(p-diarylaminostyryl)-2,5dicyanobenzene Derivatives with Large Two-Photon Absorption Cross-Sections", Org. Lett. 5, 645-648, 2003.

28. A. Abbotto, L. Beverina, R. Bozio, A. Facchetti, C. Ferrante, G. A. Pagani, D. Pedron and R. Signorini, "Novel heteroaromatic-based multi-branched dyes with enhanced two-photon absorption activity", Chem. Commun., 2144-2145, 2003.

29. O. Mongin, J. Brunel, L. Porrès and M. Blanchard-Desce, "Synthesis and Two-Photon Absorption of Triphenylbenzene-Cored Dendritic Chromophores", Tetrahedron Lett. 44, 2813-2816, 2003. 
30. O. Mongin, L. Porrès, C. Katan, T. Pons, J. Mertz and M. Blanchard-Desce, "Synthesis and two-photon absorption of highly soluble three-branched fluorenylene-vinylene derivatives", Tetrahedron Lett. 44, 8121$8125,2003$.

31. L. Porrès, O. Mongin, C. Katan, M. Charlot, T. Pons, J. Mertz and M. Blanchard-Desce, "Enhanced TwoPhoton Absorption with Novel Octupolar Propeller-Shaped Fluorophores Derived from Triphenylamine", Org. Lett. 6, 47-50, 2004.

32. L. Porrès, C. Katan, O. Mongin, T. Pons, J. Mertz and M. Blanchard-Desce, "Two-Photon Absorption and Fluorescence in Nanoscale Multipolar Chromophores: Effect of dimensionality and charge-symmetry", J. Mol. Struct., in press.

33. L. Porrès, O. Mongin, C. Katan, M. Charlot, B. K. G. Bhatthula, T. Pons, J. Mertz and M. Blanchard-Desce, "Two-Photon Absorption and Fluorescence with Quadrupolar and Branched Chromophores. Effect of Structure and Branching", J. Nonlin. Opt. Phys. Mat., in press.

34. A. Adronov, J. M. J. Fréchet, G. S. He, K.-S. Kim, S.-J. Chung, J. Swiatkiewicz and P. N. Prasad, "Novel TwoPhoton Absorbing Dendritic Structures." Chem. Mater. 12, 2838-2841, 2000.

35. M. Drobizhev, A. Karotki, A. Rebane and C. W. Spangler, "Dendrimer molecules with record large two-photon absorption cross section", Opt. Lett. 26, 1081-1083, 2001.

36. M. Drobizhev, A. Karotki, Y. Dzenis, A. Rebane, Z. Suo and C. W. Spangler, "Strong Cooperative Enhancement of Two-Photon Absorption in Dendrimers", J. Phys. Chem. B 107, 7540-7543, 2003.

37. C. W. Spangler, Z. Suo, M. Drobizhev, A. Karotki and A. Rebane, "New organic dendrimers with greatly enhanced multi-photon absorption for photonics applications", NATO Science Ser., II: Math., Phys. and Chem. 100, 139-153, 2003.

38. M. Ranger and M. Leclerc, "New Base-Doped Polyfluorene Derivatives", Macromolecules 32, 3306-3313, 1999.

39. J. N. Demas and G. A. Crosby, "The Measurement of Photoluminescence Quantum Yields. A Review", J. Phys. Chem. 75, 991-1024, 1971.

40. C. Xu and W. W. Webb, "Measurement of two-photon excitation cross sections of molecular fluorophores with data from 690 to $1050 \mathrm{~nm} "$, J. Opt. Soc. Am. B 13, 481-491, 1996.

41. M. A. Albota, C. Xu and W. W. Webb, "Two-photon fluorescence excitation cross sections of biomolecular probes from 690 to $960 \mathrm{~nm}$ ", Appl. Opt. 37, 7352-7356, 1998.

42. M. J. Frisch, G. W. Trucks, H. B. Schlegel, G. E. Scuseria, M. A. Robb, J. R. Cheeseman, V. G. Zakrzewski, J. A. Montgomery Jr., R. E. Stratmann, J. C. Burant, S. Dapprich, J. M. Millam, A. D. Daniels, K. N. Kudin, M. C. Strain, O. Farkas, J. Tomasi, V. Barone, M. Cossi, R. Cammi, B. Mennucci, C. Pomelli, C. Adamo, S. Clifford, J. Ochterski, G. A. Petersson, P. Y. Ayala, Q. Cui, K. Morokuma, D. K. Malick, A. D. Rabuck, K. Raghavachari, J. B. Foresman, J. Cioslowski, J. V. Ortiz, B. B. Stefanov, G. Liu, A. Liashenko, P. Piskorz, I. Komaromi, R. Gomperts, R. L. Martin, D. J. Fox, T. Keith, M. A. Al-Laham, C. Y. Peng, A. Nanayakkara, C. Gonzalez, M. Challacombe, P. M. W. Gill, B. Johnson, W. Chen, M. W. Wong, J. L. Andres, M. Head-Gordon, R. E. S. and J. A. Pople: Gaussian 98, Revision A.11, Gaussian, Inc., Pittsburgh PA, 2001.

43. A. D. Becke, "Density-functional thermochemistry. III. The role of exact exchange", J. Chem. Phys. 98, 5648$5652,1993$.

44. MOLEKEL 4.0; P. Flükiger, H. P. Lüthi, H., S. Portmann and J. Weber, Swiss Center for Scientific Computing, Manno (Switzerland), 2000.

45. M. G. Kuzyk, "Fundamental limits on two-photon absorption cross sections", J. Chem. Phys. 119, 8327-8334, 2003.

46. C. Hansch, A. Leo and R. W. Taft, "A Survey of Hammett Substituent Constants and Resonance and Field Parameters", Chem. Rev. 91, 165-195, 1991.

47. P. Macak, Y. Luo, P. Norman and H. Ågren, "Electronic and vibronic contributions to two-photon absorption of molecules with multi-branched structures", J. Chem. Phys. 113, 7055-7061, 2000.

48. D. Riehl, N. Izard, M. Charlot, O. Mongin and M. Blanchard-Desce, to be published. 